\title{
Multiple bronchial stenoses: treatment by mechanical dilatation
}

\author{
PB ILES
}

From the Royal Liverpool Hospital and Regional Cardiothoracic Centre, Broadgreen Hospital, Liverpool

ABSTRACT Four patients with multiple bronchial stenoses are described. Two patients had pulmonary sarcoidosis, the third probably had berylliosis, and the aetiology is unknown in the fourth Their symptoms included dyspnoea, wheeze, stridor, and frequent chest infections. The bronchial stenoses were demonstrated by tomography, flow volume studies, and bronchoscopy. Corticosteroids were ineffective but improvement followed bougie dilatation at rigid bronchoscopy.

Major bronchial stenoses may give rise to dyspnoea, stridor, and cough with purulent sputum because of recurring chest infections, or to segmental or lobar collapse if the airway obstruction is complete. Such stenoses may be malignant, post-traumatic, or postinflammatory. Tuberculosis is now a relatively rare cause but stenosis is a well-recognised if sometimes overlooked complication of sarcoidosis. ${ }^{1-4}$ We describe four patients with major bronchial stenoses treated by bougie dilatation.

\section{Case reports}

CASE 1

This patient was a 41-year-old man (EL). A diagnosis of pulmonary sarcoidosis had been made in 1971 on the basis of bilateral hilar lymphadenopathy, a negative tuberculin reaction, and a positive scalene node biopsy. He subsequently complained of increasing effort dyspnoea and recurrent bronchial infections, despite treatment with oral prednisolone from 1973 to 1978 . He presented to this unit in 1979 with dyspnoea walking slowly on level ground, stridor, a fixed wheeze at the left mid zone, and reduced breath sounds at both apices.

Pulmonary function tests showed airflow obstruction with a small residual volume (RV) and total lung capacity (TLC) (table). The flow-volume curve indicated main airways narrowing, which was confirmed on tomography.

At fibreoptic bronchoscopy there were multiple pale, fibrous-looking stenoses but the mucosa was

Address for reprint requests: Dr PB Iles, Dudley Road Hospital, Dudley Road, Birmingham B18 7QH. apparently normal. The segmental bronchi of the right upper lobe (RUL) were each narrowed to between $0.5 \mathrm{~mm}$ and $2 \mathrm{~mm}$, and the middle lobe (RML) bronchus to $3 \mathrm{~mm}$. The segmental bronchi in the superior division of the left upper lobe (LUL) were each $0.5 \mathrm{~mm}$ in diameter, the lingular bronchus was reduced to $2 \mathrm{~mm}$, and the left lower lobe (LLL) bronchus to $5 \mathrm{~mm}$.

At rigid bronchoscopy only the RML and the LLL bronchial stenoses were accessible to dilatation under direct vision; the former was dilated from 3 to $9 \mathrm{~mm}$ and the latter from 5 to $9 \mathrm{~mm}$. Bronchial biopsy showed submucosal fibrosis only.

After dilatation there was immediate improvement in pulmonary function (table). The stridor was abolished, there were no further bronchial infections, and the patient was able to climb six flights of stairs without stopping. This improvement has now been sustained for 18 months with the help of a second dilatation nine months after the first.

CASE 2

This 32-year-old woman (EM) was referred in 1979 with a three-year history of wheeze and stridor caused by endobronchial sarcoidosis. This diagnosis had been made by bronchial biopsy in 1976 when a stenosis of the left main bronchus was found at bronchoscopy. The Kveim test was also positive. Systemic steroids (prednisolone) and oral bronchodilators had not helped, so that the patient now complained of dyspnoea walking slowly on level ground and recurring chest infections with purulent sputum. Examination revealed stridor, bilateral basal expiratory wheezes, a fixed wheeze at the left mid zone anteriorly, and diminished breath sounds at the left apex. 
Table Pulmonary function responses to bougie dilatation

\begin{tabular}{|c|c|c|c|c|c|c|c|}
\hline Patient & $F V C(l)$ & $F E V_{1}(l)$ & $P F(l / s)$ & MIF $50 \%(l / s)$ & $R V(l)$ & $T L C(l)$ & DCo $(\%)$ \\
\hline $\begin{array}{l}1 \text { Predicted } \\
\text { Before dilatation } \\
\text { After dilatation: } 48 \text { hours } \\
\qquad 3 \text { months }\end{array}$ & $\begin{array}{l}5 \cdot 1 \\
3 \cdot 6 \\
4 \cdot 8 \\
5 \cdot 0\end{array}$ & $\begin{array}{l}4 \cdot 0 \\
1 \cdot 0 \\
1 \cdot 5 \\
1 \cdot 7\end{array}$ & $\begin{array}{l}- \\
2 \cdot 1 \\
3 \cdot 0 \\
3 \cdot 7\end{array}$ & $\begin{array}{l}- \\
0 \cdot 8 \\
1 \cdot 6 \\
2 \cdot 5\end{array}$ & $\begin{array}{l}2.0 \\
1.6\end{array}$ & $\begin{array}{l}7 \cdot 4 \\
5 \cdot 2\end{array}$ & $\begin{array}{r}100 \\
81\end{array}$ \\
\hline $\begin{array}{l}2 \text { Predicted } \\
\text { Before dilatation } \\
\text { After dilatation: } 48 \text { hours } \\
\qquad 3 \text { months }\end{array}$ & $\begin{array}{l}3 \cdot 2 \\
1 \cdot 6 \\
2 \cdot 2 \\
2 \cdot 3\end{array}$ & $\begin{array}{l}1 \cdot 8 \\
1 \cdot 0 \\
1 \cdot 1 \\
1 \cdot 3\end{array}$ & $\begin{array}{l}- \\
1.6 \\
1.6 \\
2.0\end{array}$ & $\begin{array}{l}\overline{1.5} \\
1.5 \\
1 \cdot 7\end{array}$ & $\begin{array}{l}1.4 \\
0.7\end{array}$ & $\begin{array}{l}4 \cdot 8 \\
2 \cdot 9\end{array}$ & $\begin{array}{r}100 \\
64\end{array}$ \\
\hline $\begin{array}{l}3 \text { Predicted } \\
\text { Before dilatation } \\
\text { After dilatation: } 48 \text { hours } \\
\end{array}$ & $\begin{array}{l}4 \cdot 7 \\
2 \cdot 4 \\
2 \cdot 6 \\
2 \cdot 8\end{array}$ & $\begin{array}{l}3 \cdot 7 \\
1 \cdot 0 \\
1 \cdot 1 \\
1 \cdot 2\end{array}$ & $\begin{array}{l}- \\
3 \cdot 0 \\
3 \cdot 5 \\
3 \cdot 8\end{array}$ & $\begin{array}{l}- \\
4 \cdot 6 \\
4 \cdot 5 \\
4 \cdot 4\end{array}$ & $\begin{array}{l}2 \cdot 0 \\
3 \cdot 0\end{array}$ & $\begin{array}{l}6.6 \\
5.4\end{array}$ & $\begin{array}{r}100 \\
75\end{array}$ \\
\hline $\begin{array}{l}4 \text { Predicted } \\
\text { Before dilatation } \\
\text { After dilatation: } 48 \text { hours } \\
\quad 3 \text { months }\end{array}$ & $\begin{array}{l}4 \cdot 4 \\
2 \cdot 9 \\
3 \cdot 7 \\
4 \cdot 6\end{array}$ & $\begin{array}{l}3 \cdot 8 \\
1 \cdot 2 \\
1 \cdot 7 \\
2 \cdot 0\end{array}$ & $\begin{array}{l}- \\
1.9 \\
2 \cdot 7 \\
2 \cdot 9\end{array}$ & $\begin{array}{l}- \\
2 \cdot 0 \\
2 \cdot 4 \\
3 \cdot 6\end{array}$ & $\begin{array}{l}1.5 \\
1.65\end{array}$ & $\begin{array}{l}5 \cdot 9 \\
5 \cdot 25\end{array}$ & $\begin{array}{l}100 \\
100\end{array}$ \\
\hline
\end{tabular}

$\mathrm{FEV}_{1}=$ forced expiratory volume in one second $; \mathrm{FVC}=$ forced vital capacity; $\mathrm{PF}=$ peak flow rate; $\mathrm{MIF} 50 \%=$ maximal inspiratory flow at $50 \% \mathrm{VC} ; \mathrm{RV}=$ residual volume; TLC = total lung capacity; DCO $=$ transfer factor for carbon monoxide as $\%$ of predicted.

Radiographs showed reduced vascular markings in the left upper zone and contraction of the RUL. There was left hilar enlargement and narrowing of the LMB on tomography. Spirometry showed an obstructive pattern but with reduction in the RV, TLC, and DCO (table). The flow-volume loop suggested fixed airways obstruction.

At bronchoscopy the mucosa of the left bronchial tree was granular, inflamed, and oedematous. The LMB was curved and narrowed, the LUL orifice reduced to a fibrous pit, and the LLL bronchus narrowed to $4 \mathrm{~mm}$. There was a $4 \mathrm{~mm}$ stenosis of the RUL bronchus. The curve of the LMB prevented direct vision of the LLL stenosis with a rigid bronchoscope. Dilatation of the LLL bronchus was achieved by first introducing a guide wire through the stenosis via a fibreoptic bronchoscope passed down a rigid bronchoscope, and then sliding Eder Puestow dilators over the guide.

Initially there was improvement in symptoms and pulmonary function (table). Further dilatations were necessary after three and a half, seven, and nine months, each giving improvement for about three months.

\section{CAS E 3}

This 44-year-old man (JD) was referred in 1979 with dyspnoea, wheeze, and frequent chest infections. Berylliosis had been diagnosed in 1971 and dyspnoea developed in 1974. Because of progressive shrinkage of the RUL, bronchoscopy was performed in 1977 and stenoses of the RUL and RML orifices noted. Systemic corticosteroids gave some symptomatic relief but recurring bronchial infections were troublesome by 1979. At this time the patient was dyspnoeic on climbing one flight of stairs and had inspiratory and expiratory wheezes over the RUL. Radiographs showed upper lobe shrinkage, more marked on the right and increased transradiancy at the right base. Pulmonary function showed airflow obstruction with an increased residual volume (table). The flow-volume curve suggested emphysema.

At bronchoscopy the RUL segmental orifices were markedly narrowed and the RML orifice reduced to a slit. This was dilated to $8 \mathrm{~mm}$ with Chevalier Jackson bougies but it was not practicable to dilate the upper lobe bronchus.

Pulmonary function improved only slightly after dilatation (table) but the patient had no further respiratory infections requiring antibiotics in the next 10 months.

\section{CAS E 4}

This patient (RP), a 28-year-old man, presented in 1978 with a six-month history of rapidly increasing dyspnoea, stridor, wheeze, and chest infections. Corticosteroids had not helped these symptoms. A bronchoscopy three months previously had shown bilateral mucosal oedema of unknown cause, and plain radiographs and tomograms had been normal.

On examination he was dyspnoeic at rest and had a loud stridor. Breath sounds were reduced at both upper zones, with widespread inspiratory and expiratory wheezes. A flow-volume curve suggested fixed main airways obstruction (fig), spirometry showed airflow obstruction, and the RV, TLC, and DCO were normal (table). The plain radiograph was normal but tomograms now showed bilateral main bronchial narrowing.

At fibreoptic bronchoscopy the LMB was narrowed to $2 \mathrm{~mm}$, the $\mathrm{RMB}$ to $6 \mathrm{~mm}$, and the bronchus 


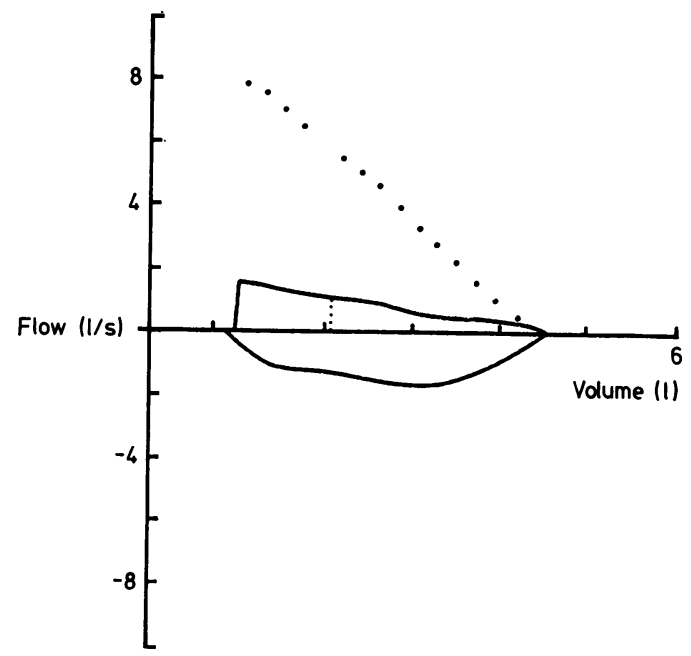

Figure Flow-volume loop of patient $4(R P)$, showing pattern suggestive of main airway obstruction.

intermedius to $3 \mathrm{~mm}$. The stenoses were pale and fibrous but the rest of the mucosa looked normal. The stenoses in both main bronchi were dilated to $9 \mathrm{~mm}$ with Chevalier Jackson bougies via a rigid bronchoscope. Systemic steroids were given for seven days to minimise post-traumatic oedema. Dilatation was repeated after six weeks.

After dilatation the dyspnoea, stridor, and pulmonary function improved. Further dilatations were necessary six months and 15 months after the first but on each occasion the stenoses were less marked. Bronchial biopsy showed fibrosis beneath normal epithelium. The patient is working and playing football regularly with only slight stridor two years after the first dilatation.

\section{Discussion}

Sarcoidosis usually causes a restrictive spirometric pattern $^{6}$ but airways obstruction is also well described and often overlooked. There may be large airways obstruction, ${ }^{1-4} 7$ small airways obstruction, ${ }^{89}$ or both. ${ }^{10}$ Stenosis of main, lobar, or segmental bronchi were found in only eight of 99 sarcoid patients bronchoscoped by Olssen et al. ${ }^{4}$ Corticosteroids sometimes help bronchostenoses 251011 and sometimes do not. ${ }^{411}$ Mechanical dilatation of sarcoid bronchostenoses has rarely been recorded; Olssen et al describe using the tip of a fibreoptic bronchoscope in one patient but with little real benefit. ${ }^{4}$ Our four patients had all received systemic steroids, with little clinical benefit, before referral.
It was this failure and the potentially fatal stenoses in patient 4 that made us consider mechanical dilatation.

We have found that upper lobe stenoses seem to contribute little to dyspnoea as illustrated by patient 1 whose dyspnoea was almost totally abolished by dilatation of the lower and middle lobe bronchi, although the segmental orifices of his upper lobes were each $0.5 \mathrm{~mm}$ or less. This is not surprising since in a healthy and upright subject the upper lobes receive less blood supply than the lower lobes and contribute less to gas exchange. This is important since all four of our patients had upper lobe stenoses which were inaccessible to dilatation via a rigid bronchoscope.

In patients 1 and 4 , bronchial dilatation immediately improved symptoms of dyspnoea, wheeze, and infection, but after three or four months free from infection there had been further improvement clinically and in pulmonary function. It is possible that recurrent infection may have added a reversible inflammatory component to the strictures.

Rigid bronchoscopy and bougie dilatation were performed by Mr RJ Donnelly. I am grateful to Dr J Delaney, Dr CC Evans, and Dr CM Ogilvie for permission to report their patients and for their helpful advice in the preparation of the manuscript, and to Mrs B Mann and Miss L Laffey for their typing.

\section{References}

${ }^{1}$ Citron KM, Scadding JG. Stenosing non-caseating tuberculosis (sarcoidosis) of the bronchi. Thorax 1957;12: 10-17.

${ }^{2}$ Honey M, Jepson E. Multiple bronchostenoses due to sarcoidosis. Br Med J 1957;2:1330-4.

${ }^{3}$ Wescott JL, Noehren TH. Bronchial stenosis in chronic sarcoidosis. Chest $1973 ; 63: 893-7$.

${ }^{4}$ Olssen T, Bjornstad-Petterson H, Stjernberg N. Bronchostenosis due to sarcoidosis. Chest 1979;75:663-6.

${ }^{5}$ Mathews JI, Hooper RG. Idiopathic bronchial stenosis in a young woman. Chest 1978;74:190-1.

- Bates DV, Macklem PT, Christie RV. Respiratory function in disease. Second edition. Philadelphia: WB Saunders Company, 1971:289.

${ }^{7} \mathrm{Di}$ Bendetto RJ, Ribaudo C. Bronchopulmonary sarcoidosis. Am Rev Respir Dis 1966;64:952-5.

${ }^{8}$ Miller A, Teirstein AS, Jacker I, Chuang M, Siltzbach LE. Airways function in chronic pulmonary sarcoidosis with fibrosis. Am Rev Respir Dis 1974;109:179-89.

${ }^{9}$ Levinson RS, Metzger LF, Stanley NN et al. Airway function in sarcoid. Am J Med 1977;62:51-9.

10 Benatar SR, Clark TJH. Pulmonary function in a case of endobronchial sarcoidosis. Am Rev Respir Dis 1974; 110:490-6.

${ }^{11}$ Stone DJ, Schwartz A, Feltman JA, Lovelock F. Pulmonary function in sarcoidosis. Am J Med 1953;15: 468-76. 